\title{
KAMPANYE PENANGKALAN HOAX MELALUI APLIKASI GAWAI
}

\author{
Calvin Palti Junjungan Sinaga, Jessica Yonatia \\ (Email: calvin.palti@gmail.com) \\ Program Studi Desain Komunikasi Visual \\ Fakultas Seni Rupa dan Desain \\ Universitas Kristen Maranatha \\ Jl. Prof. Drg. Surya Sumantri No.65, Bandung, Jawa Barat, 40164, Indonesia
}

\begin{abstract}
ABSTRAK
Hoax merupakan suatu istilah yang tidak asing bagi netizen (pengguna internet) dewasa ini, berarti sebuah kebohongan yang sengaja dibuat dan disebarkan secara tidak bertanggung jawab melalui media internet. Hoax menjadi suatu hal yang meresahkan dan menyesatkan mayoritas netizen yang menerima berita melalui internet, namun seringkali sumber berita tidak kredibel justru menjadi sarana utama penyebaran hoax. Dampak terburuk hoax yang dapat terjadi adalah terpecah belahnya kesatuan bangsa melalui isu SARA. Hoax sendiri sebenarnya bukanlah sesuatu yang sulit untuk dilawan apabila netizen memiliki pengetahuan literasi media, yaitu sikap kritis terhadap pemberitaan yang menjadikan netizen dapat lebih kritis menyaring berita yang tersebar di internet. Oleh karena itu, perlu dibuat perancangan kampanye sosial mengenai pengetahuan literasi media kepada netizen di kota-kota besar di Indonesia. Metode perancangan visual dalam kampanye ini menggunakan kompilasi fotografi dan vektor bergaya pop art, dengan media utama aplikasi gawai dan media pendukung yang terdiri dari poster berseri di media sosial, mini event, website dan gimmick. Tujuan perancangan kampanye ini adalah mengedukasi netizen mengenai literasi media yang akan memunculkan sikap kritis dan selektif terhadap berita yang tersebar di internet.
\end{abstract}

Kata Kunci: aplikasi gawai; hoax; kampanye; literasi media; netizen

\begin{abstract}
The hoax is known as a familiar term for netizen nowadays, which its meaning is a public lie that made and spread irresponsibly through the internet. The hoax has become something that troubling yet misleading the netizen since they majority netizen receives news through the internet without noticing the credibility of the authors. The worst impact of hoax would be the split of the nation's unity. Hoax itself is not something that hard to be opposed to if the netizen has media literacy knowledge, which is having a critical attitude to the news that spread through the internet. Therefore, this social campaign about educating media literacy was created towards netizen in the big cities of Indonesia. The design method used in this campaign is using a visual compilation of photography and pop art vector, with gadget application as the main media, and the supporting medias such as a serial poster in social media, mini event, website, and gimmick. The main goal of this campaign is to educate netizen about media literacy and the next expected goal is the appearance of critical and selective attitude towards news that spread on the internet.
\end{abstract}

Keywords: application; campaign; gadget; hoax; media literacy; netizen

\section{PENDAHULUAN}

Di abad ke-21 ini fenomena internet menjadi sangat marak, dan banyak hal yang menyangkut kepentingan hidup manusia berubah dari cara konvensional menjadi modern 
seperti online. Hal ini berlaku juga dalam komunikasi dan penyebaran informasi melalui dunia maya. Sebelum memasuki era internet, pemberitaan hanya dapat diakses melalui tv, radio atau media cetak melalui koran dan majalah. Namun, kini segala jenis berita dapat diakses secara mudah dan cepat melalui website, media sosial, atau portal berita online lainnya. Dalam era internet, semua individu dapat menjadi seorang publisher yang memproduksi informasi, menyusun berita dan menyebarkannya. Hal tersebut terbukti dari meningkatnya nominal individu yang diamankan kepolisian Indonesia karena menyusun dan menyebarkan berita hoax.

Bergesernya penyebaran berita dari media konvensional ke media internet ini menimbulkan pro dan kontra. Sisi positif yang muncul adalah segala jenis informasi dapat diperoleh secara cepat dan mudah. Namun, sisi negatif timbul saat kemudahan di atas dimanfaatkan oleh oknum tak bertanggung jawab yang menyusun dan menyebarkan berita tidak benar (hoax), dengan motif yang variatif seperti: politik, SARA, ekonomi, modus penipuan, bahkan sampai menanamkan pola pikir negatif secara psikologis kepada netizen (masyarakat pengguna internet). Menurut survei yang dilakukan Depkominfo pada tahun 2016, terdapat 800.000 situs penyebar hoax, dan $76 \%$ di antaranya memiliki motif politik dan SARA.

Ketua Masyarakat Anti Hoax Indonesia, Septiaji Eko Nugroho (2018) dalam suatu wawancara mengungkapkan cepatnya penyebaran informasi dan berita pada netizen sayangnya tidak diimbangi dengan sikap kritis terhadap berita itu sendiri. Dalam era internet ini, masyarakat dengan sangat mudah mengakses informasi, namun tidak disertai dengan kesadaran literasi media yang cukup, sehingga terjadi budaya menyebarkanluaskan informasi yang belum tentu valid dan faktual.

Berdasarkan survei yang dilakukan penulis pada bulan September 2017, kepada 150 responden kalangan menengah dan menengah bawah di kota Bandung, dengan rentang usia 18-30 tahun, mengungkapkan bahwa 95\% mereka pernah merasa resah akibat membaca berita yang ternyata hoax, dan $83 \%$ merupakan berita yang berkaitan dengan isu SARA. Hal tersebut menjadi masalah yang sangat sensitif di Indonesia yang merupakan negara dengan keanekaragaman suku bangsa, budaya, adat istiadat, dan agama. Terlebih lagi Jika netizen menanggapi sebuah berita dengan konten SARA dengan emosional dan tidak rasional, dampak terburuk yang dapat terjadi adalah pecahnya kesatuan dan 
persatuan bangsa. Oleh karenanya, untuk mengatasi masalah tersebut diperlukan sebuah perancangan kampanye sosial mengenai pentingnya literasi media pada netizen di kota Bandung, dengan harapan penyebaran hoax dapat diminimalisir dan tercipta arus komunikasi online yang kondusif dan kredibel.

\section{METODE PERANCANGAN}

Perancangan kampanye dilakukan dalam beberapa tahap. Pada tahap pertama dilakukan pengumpulan data melalui wawancara, studi banding, studi literatur dan kuesioner. Pada tahap kedua dilakukan analisis terhadap data tersebut, dan pada tahap ketiga disusun konsep perancangan yang meliputi konsep komunikasi, konsep kreatif, dan konsep media. Adapun studi pustaka yang mendukung perancangan ini adalah sebagai berikut:

\section{Model Kampanye Leon Ostergaard}

Kampanye merupakan rangkaian aktivitas yang dilakukan secara sistematis dan teroganisir dalam kurun waktu tertentu, dengan tujuan untuk mendorong perubahan perilaku dan pola pikir masyarakat (Venus, 2004: 7). Model kampanye yang diterapkan sebagai upaya komunikasi agar pesan kampanye dapat tersalur dengan baik, adalah model kampanye dari Leon Ostergaard. Kampanye ini dibagi menjadi 3 tahapan periode waktu pelaksanaan demi tercapainya pesan kampaye yang maksimal, yaitu : Awareness, Informing dan Reminding.Tahap awal yaitu awareness dilakukan untuk menarik perhatian netizen tentang adanya isu yang menjadi fokus utama kampanye, kemudian tahap selanjutnya adalah informing untuk memberikan informasi secara detail tentang pesan kampanye, sehingga diharapkan akan menimbulkan minat dan kesadaran akan tujuan utama kampanye. Tahap akhir adalah reminding yang bertujuan mengingatkan kembali netizen mengenai pesanpesan komunikasi yang telah disampaikan pada dua tahapan sebelumnya, dengan harapan terjadi perubahan perilaku dan pola pikir yang berkelanjutan.

\section{Literasi Media}

Literasi media adalah istilah yang populer digunakan di Indonesia untuk menyebut berbagai aktivitas yang terkait dengan sikap kritis terhadap media.

Literasi media dibagi menjadi 3 kategori berdasarkan tingkat kemampuan kecakapan seseorang, yaitu : 
- Literasi media tingkat awal berupa pengenalan media, terutama potensi efek negatif dan positif yang dapat ditimbulkan oleh media tersebut.

- Literasi media tingkat menengah yang bertujuan menumbuhkan kepekaan dan kecakapan dalam memahami konten dalam sebuah media.

- Literasi media tingkat lanjut yaitu pada tahap ini mulai terbangun kemampuan memberi kritik dan saran terhadap sebuah media yang terbukti secara konkret melanggar aturan komunikasi sosial (Purba, 2015).

\section{Definisi Hoax}

Dalam bahasa Inggris, definisi kata hoax adalah "deliberately fabricated falsehood made to masquerade as truth", yang berarti sebuah kebohongan yang secara sengaja dibuat dan "menyamar" seolah berita itu adalah sebuah kebenaran (Juliswara, 2017).

Hoax bukan sesuatu yang baru dan sudah banyak beredar sejak Johannes Gutenberg menemukan mesin cetak pada tahun 1439. Zaman sekarang seiring majunya teknologi dan internet yang membuat seseorang dapat dengan mudah menerima maupun membuat pesan, prosentase hoax melesat naik dan otomatis menimbulkan situasi tidak kondusif dalam kehidupan sosial masyarakat. Terdapat 3 kategori hoax, yaitu:

- Proper Hoax, yaitu berita yang murni sengaja disusun untuk menyesatkan dan menipu pembacanya.

- Yay Headline, Nay Content, yaitu berita yang memiliki headline yang sangat menarik dan membangkitkan keingintahuan, namun kontras dengan kualitas konten yang dikandungnya.

- Same News, Different Context, yaitu berita yang faktual namun memiliki detail yang diubah sehingga tidak sesuai dengan fakta, misalnya tanggal dan lokasi (Hurlock, 1995: 440).

\section{PEMBAHASAN}

Hasil analisis dari data yang didapat, mengungkapkan bahwa di Indonesia pada tahun 2016, terdapat 800.000 situs penyebar hoax, dan $76 \%$ di antaranya memiliki motif politik dan SARA. Hal itu terjadi juga di kalangan menengah dan menengah bawah di kota Bandung, dengan rentang usia 18-30 tahun dan membawa keresahan. Terjadinya permasalahan tersebut karena masyarakat dengan sangat mudah mengakses informasi, 
namun tidak disertai dengan kesadaran literasi media yang cukup. Oleh karenanya, penulis merancang sebuah kampanye sosial mengenai pentingnya literasi media pada netizen di kota Bandung yang dilengkapi dengan media utama aplikasi gawai yang dapat melakukan verifikasi kebenaran informasi.

\section{STP Perancangan Kampanye}

STP Perancangan Kampanye ini adalah pria dan wanita di kota Bandung berusia 18-30 tahun, berprofesi sebagai mahasiswa, wirausaha/karyawan dengan tingkat pendidikan SMA/perguruan tinggi, dan memiliki status sosial B, BC (menengah ke bawah). Secara psikografis memiliki kehidupan sosial media yang aktif dan rajin menyimak berita terbaru melalui internet, namun belum memiliki kemampuan untuk menyaring informasi secara kritis. Positioning kampanye ini adalah kampanye yang mengedukasi literasi media sebagai sikap kritis terhadap kebenaran berita online yang beredar.

\section{Konsep Komunikasi Perancangan Kampanye}

Kampanye edukasi literasi media ini diberi nama "Beraksi Hantam Hoax". Kata "beraksi" sendiri merupakan akronim dari "Baca Cermati Verifikasi". Kata "beraksi" menjadi tagline kampanye karena 3 hal tersebut merupakan tahapan proses berpikir kritis dalam menyikapi berita online yang beredar. Menurut Kamus Besar Bahasa Indonesia, kata "hantam"memiliki arti 'menghabiskan dan sebagainya dengan sekaligus', yang sangat sesuai dengan tujuan kampanye yang menginginkan netizen mampu memerangi hoax sampai tuntas dan tanpa kompromi melalui Beraksi (Baca Cermati Verifikasi).

\section{Konsep Kreatif Perancangan Kampanye}

Nama kampanye ini adalah "Beraksi Hantam Hoax", tujuan utamanya agar target audience, dalam kasus ini adalah netizen, memiliki wawasan mengenai literasi media dan kritis terhadap berita yang tersebar melalui media sosial. Diharapkan melalui kampanye ini netizen senantiasa menerapkan pola pikir sesuai dengan tagline kampanye, yaitu "baca cermati dan verifikasi".

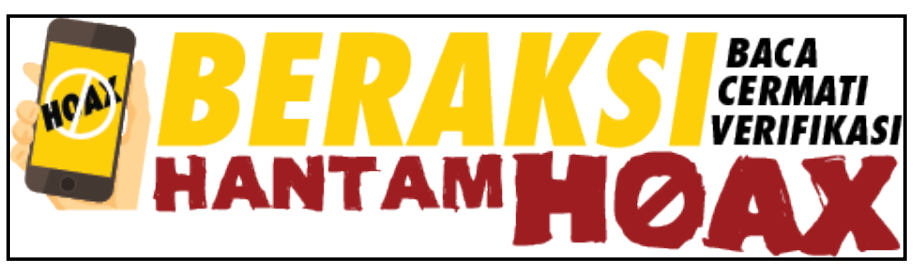

Gambar 1. Logo kampanye dilengkapi dengan tagline Sumber : penulis, 2017 
Kampanye ini menggunakan maskot dengan figur smartphone berpakaian detektif yang karakternya selalu mencari tahu kebenaran dengan cermat dan cenderung mengambil keputusan yang logis dan rasional; sesuai dengan tagline kampanye, yakni "baca cermati verifikasi". Maskot dinamakan Si Aksi, yang diambil dari kata "beraksi".

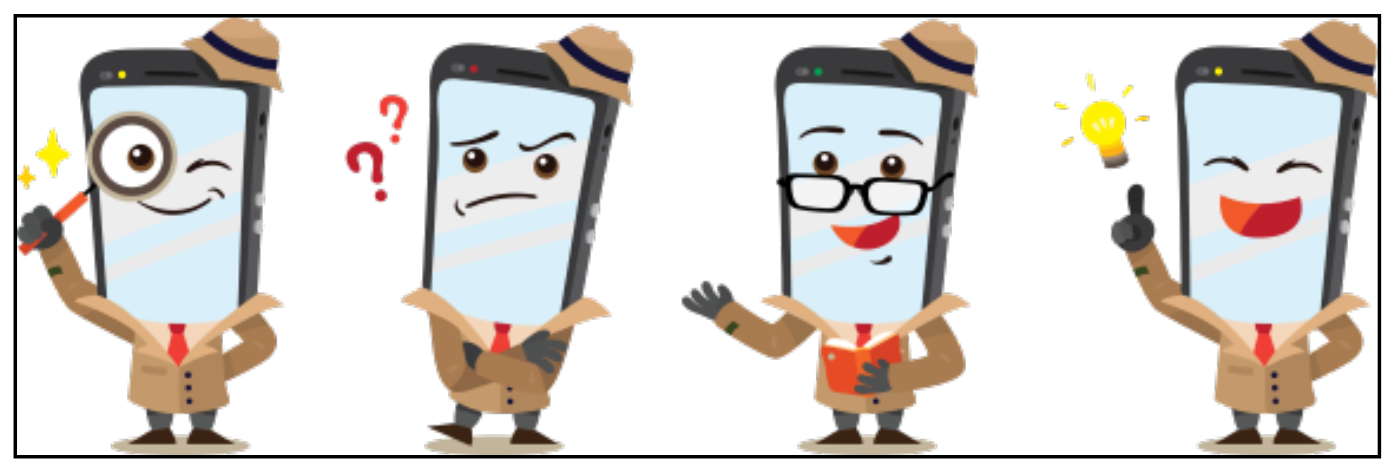

Gambar 2. Maskot kampanye Si Aksi

Sumber : penulis, 2017

Tahapan dalam kampanye "Beraksi Hantam Hoax" dibagi menjadi 3, yaitu:

a. Awareness

Pada tahap awal ini, strategi yang diterapkan adalah untuk menarik perhatian target audience mengenai topik kampanye sehingga mereka diharapkan sadar akan keberadaan literasi media untuk meminimalisir berita hoax. Pada tahap awareness, poster berseri akan diunggah ke website dan media sosial yaitu Instagram, Facebook, dan Twitter. Konten yang terkandung di dalamnya merupakan reaksi-reaksi umum netizen saat membaca berita yang ternyata hoax, seperti bingung, marah tak beralasan, dan keinginan untuk menyebar kembali berita tersebut. Warna background poster berseri pada tahap ini adalah biru muda, sebagai representasi dari ketenangan dan kecerdasan intelektual. Belum banyak informasi mendalam tentang konten kampanye pada tahap ini, dengan tujuan menarik rasa penasaran dan keingintahuan netizen. 


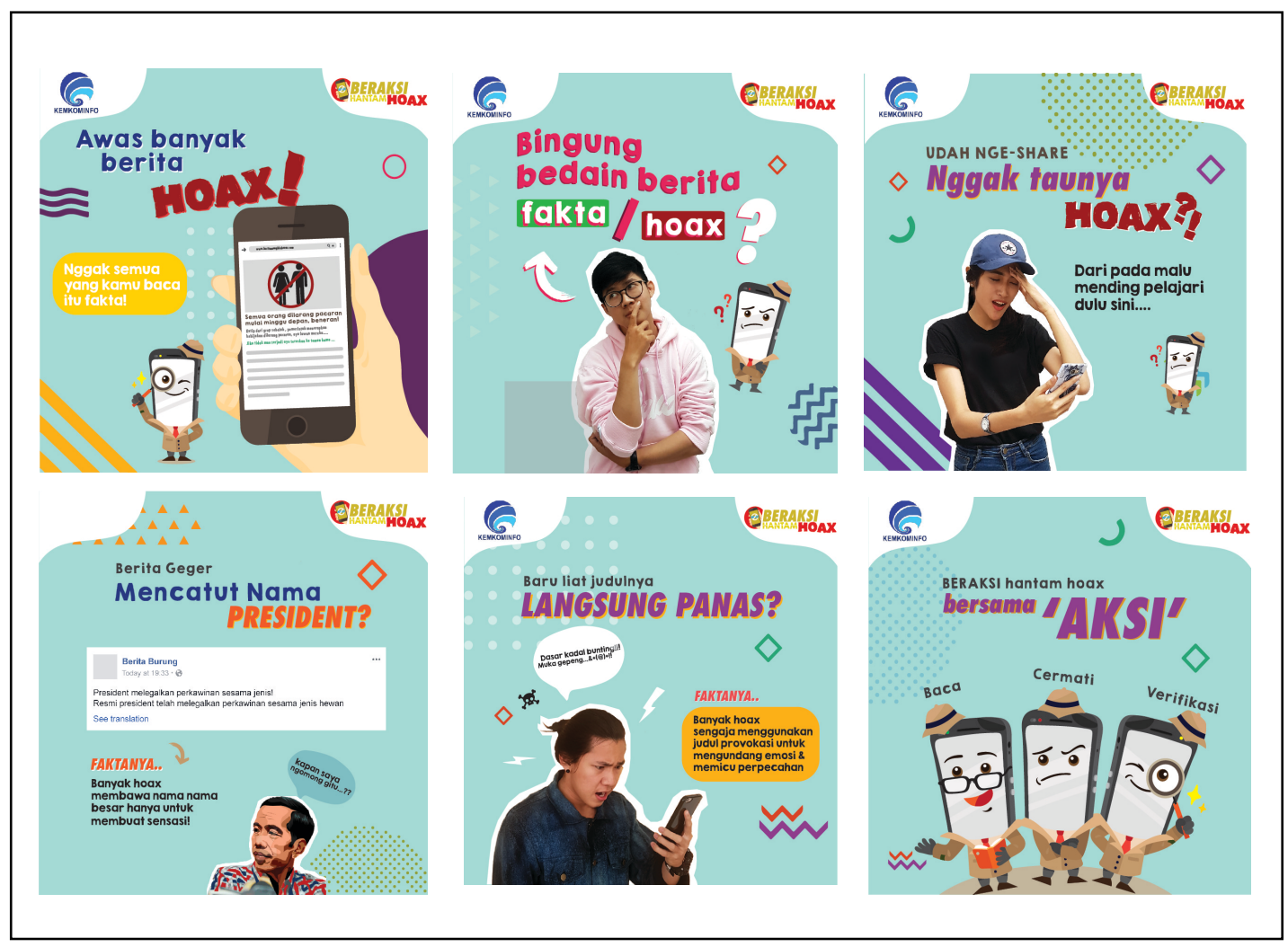

Gambar 3. Poster Awareness

Sumber : penulis, 2017

\section{b. Informing}

Tahap ini merupakan tahap esensial yang berisi informasi lengkap mengenai topik kampanye, yang pada puncaknya diluncurkan aplikasi yang dapat diunduh langsung dari gawai sehingga target audience dapat melakukan verifikasi berita dengan mudah. Informasi yang terkandung pada tahap ini sangat lengkap dan bertahap, mulai dari edukasi literasi media, penjabaran bahayanya berita hoax, sampai cara untuk melakukan verifikasi kebenaran suatu berita online dengan tepat dan mudah, melalui website dan poster berseri di media sosial. Aplikasi gawai juga diluncurkan kepada publik pada tahap ini, yang dapat diunduh langsung oleh netizen via smartphone. Pada tahap ini, layanan click ads dan layanan chatting line berfungsi sebagai sarana yang mengiklankan aplikasi ini. Aplikasi ini berfungsi untuk melakukan proses verifikasi terhadap suatu berita yang tersebar online, dan mampu menginformasikan netizen tentang status berita tersebut, apakah hoax atau benar adanya. Konsep verbal dengan gaya bahasa persuasif dan kasual diterapkan sesuai dengan segmentasi target audience. 
Serat Rupa Journal of Design, July 2018, Vol.2, No.2: 119-129

Calvin Palti Junjungan Sinaga, Jessica Yonatia

Kampanye Penangkalan Hoax Melalui Aplikasi Gawai

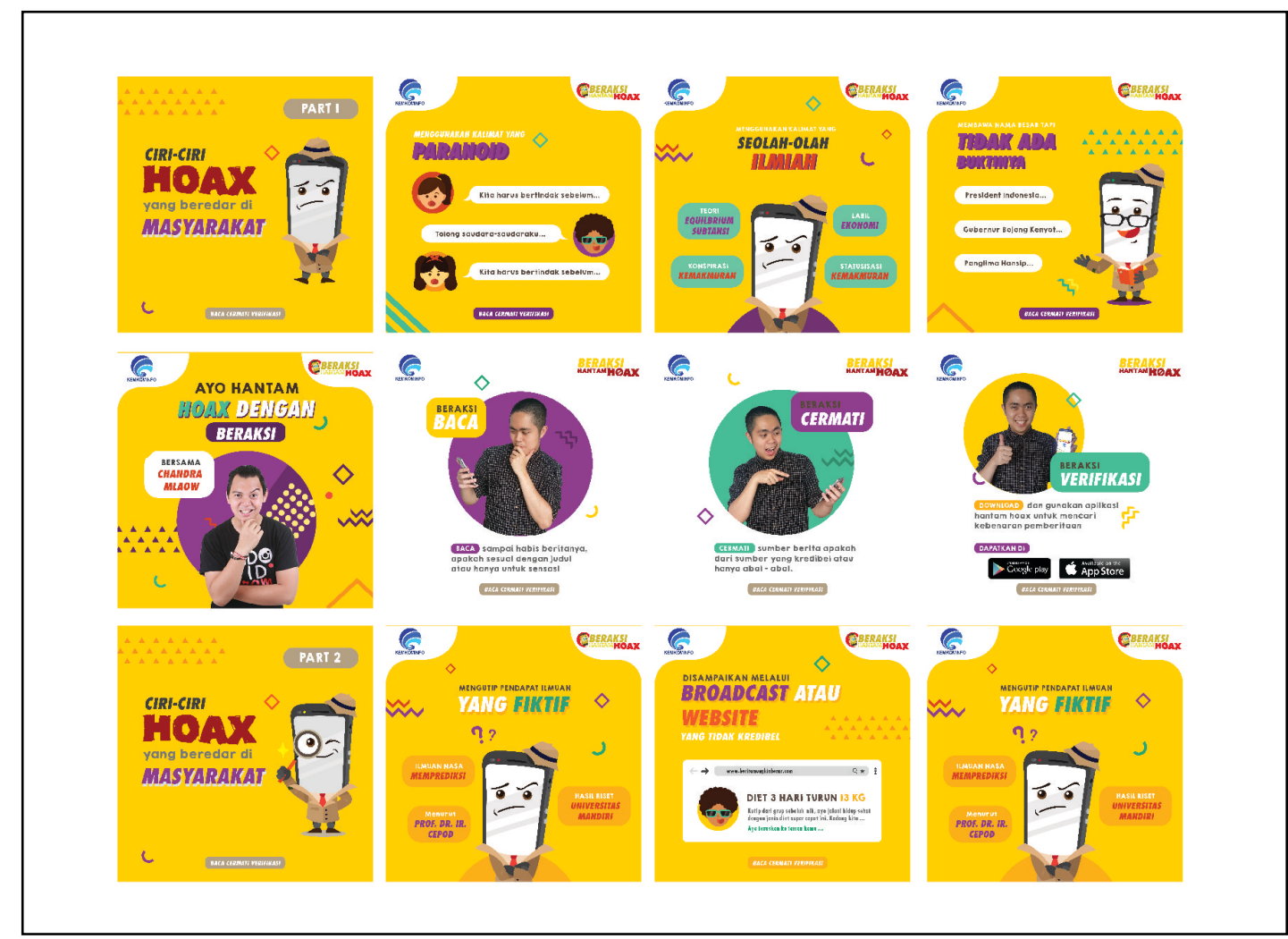

Gambar 4. Poster Informing Sumber : penulis 2017

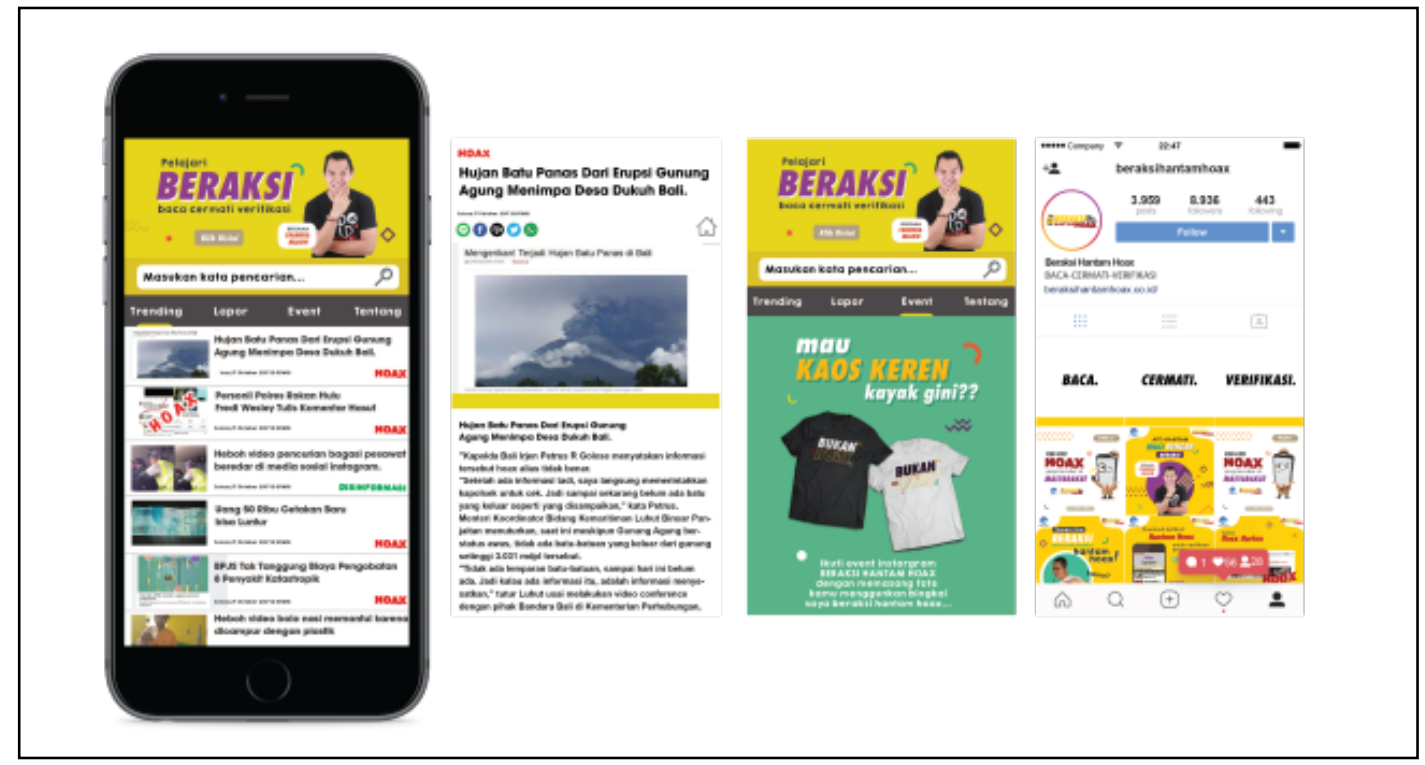

Gambar 5. Aplikasi gadget

Sumber : penulis 2017 


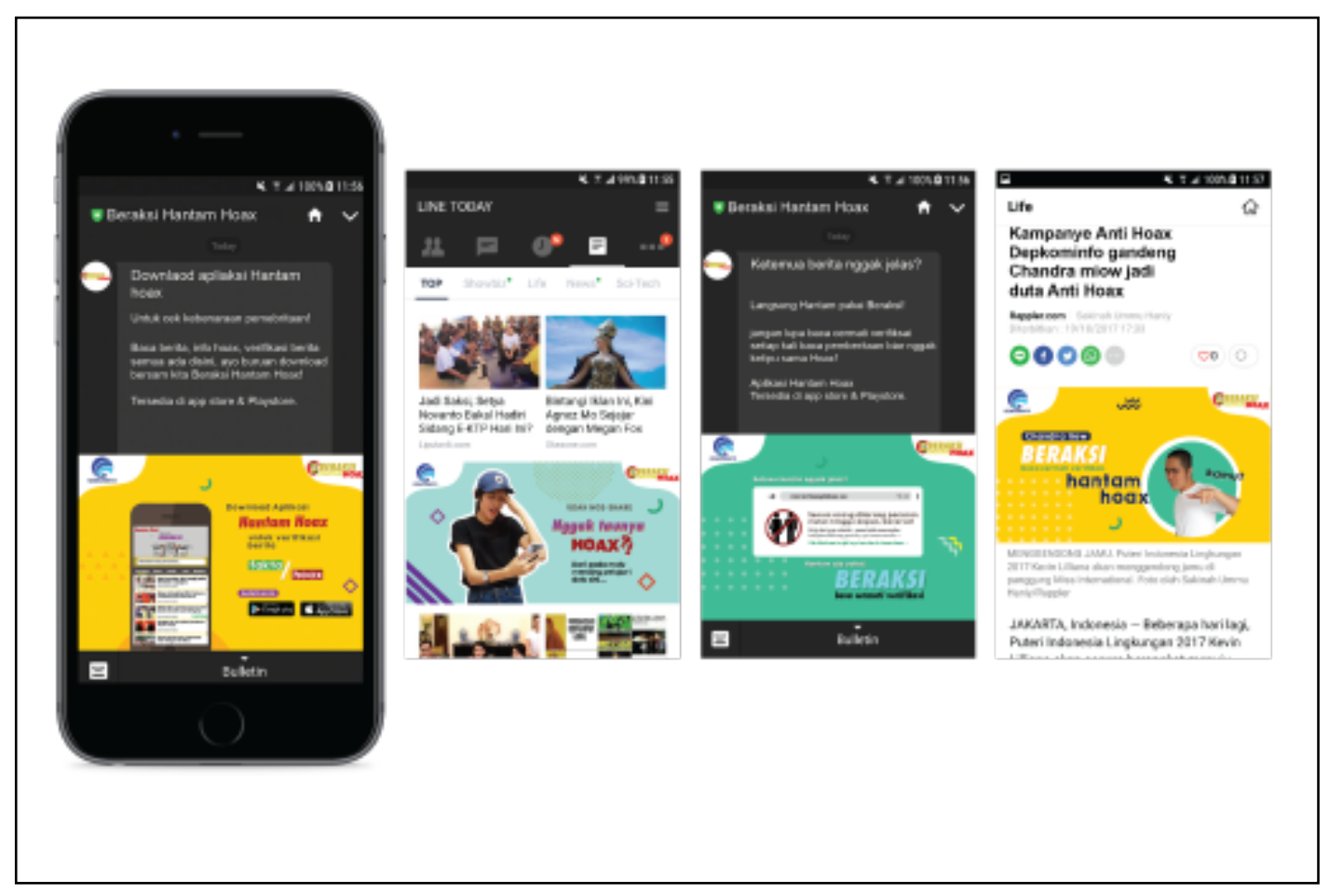

Gambar 6. Layanan chatting Line

Sumber : penulis 2017

\section{c. Reminding}

Strategi yang diterapkan pada tahap ini adalah untuk mengingatkan kembali pada target audience agar selalu waspada dan melakukan verifikasi sebelum mempercayai dan menyebarluaskan suatu berita. Pada tahap terakhir ini, poster berseri media sosial menggunakan warna background hijau toska yang cerah dan sejuk. Media lain yang digunakan adalah website dan aplikasi gawai yang terus menerus diperbaharui mengenai edukasi literasi media, dan informasi-infomasi lain seputar berita online. Aplikasi gawai juga mempunyai fitur pengingat, dengan harapan target audience dapat selalu ingat untuk melakukan verifikasi terlebih dahulu sebelum merespon ataupun menyebarkannya kembali. 


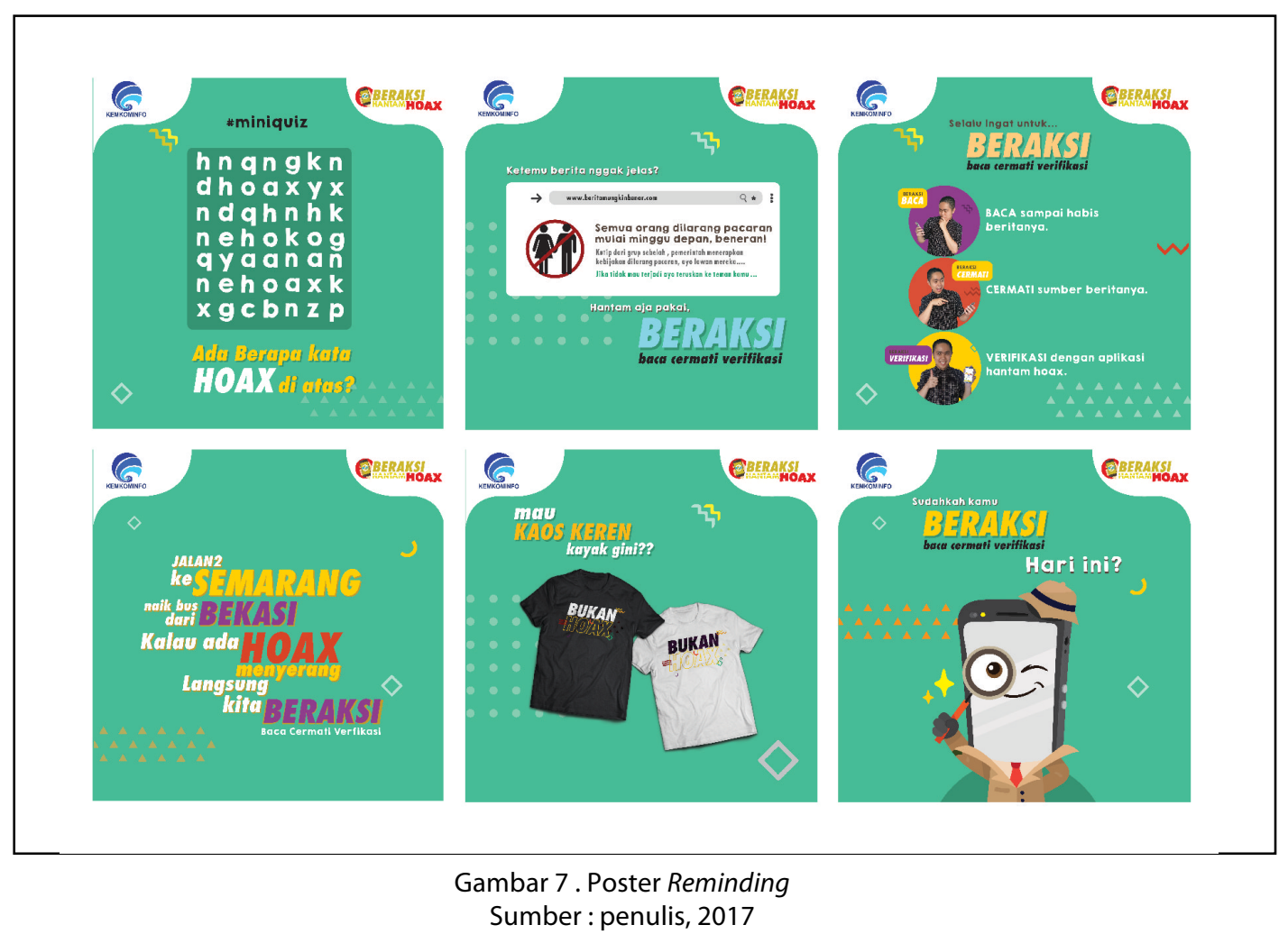

\section{PENUTUP}

Permasalahan yang terjadi adalah sebagian besar netizen (pengguna internet) sering mendapatkan berita hoax yang berkonten SARA. Majunya media internet dimanfaatkan secara negatif oleh oknum tak bertanggung jawab yang sengaja menyebar berita hoax, dengan tujuan menanamkan rasa benci, gelisah, curiga, bingung, dan titik kritisnya dapat memecah belah persatuan dan kesatuan bangsa. Melalui kampanye sosial "Beraksi Hantam Hoax" yang dilengkapi dengan media aplikasi gawai, netizen dapat melakukan verifikasi kebenaran suatu berita online dengan tepat dan mudah sebelum merespon atau menyebarkannya kembali, sehingga penyebaran informasi online tetap kondusif.

\section{DAFTAR PUSTAKA}

Hurlock, Elizabeth. 1995. Developmental Psychology. Jakarta : A Life Span Approach Juliswara, Vibriza. (2017). Mengembangkan Model Literasi Media yang Berkebhinekaan dalam Menganalisis Informasi Berita Palsu (Hoax) di Masyarakat. Jurnal Pemikiran Sosiologi, 4, (2), 142-144 
Nugroho, S.E. (2018). The phenomenon of using digital technology to deliberately spread $\begin{array}{llllll}\text { falsehoods online. } & \text { Diunduh } & 8 & \text { Mei } & 2018 & \text { dari }\end{array}$ https://www.parliament.gov.sg/docs/default-source/sconlinefalsehoods/writtenrepresentation-61.pdf

Purba, Rebekka. (2015). TINGKAT LITERASI MEDIA PADA MAHASISWA (Studi Deskriptif Pengukuran Tingkat Literasi Media Berbasis Individual Competence Framework Pada Mahasiswa Departemen IImu Komunikasi USU). Jurnal Flow, 2, (9), 3-5

Venus, Antar. (2004). Manajemen Kampanye: Paduan Teoritis dan Praktis Dalam Mengefektifkan Kampanye Komunikasi. Bandung : Simbiosa. 